\title{
Associations between Chinese Parents' Reading Beliefs, Home Literacy Practices, Children's Reading Interests and Literacy Development
}

\author{
Wei TENG ${ }^{1,{ }^{*}}$, Rachelle K. HACKETT ${ }^{2}$ and Marilyn E. DRAHEIM ${ }^{3}$ \\ ${ }^{1}$ Shanghai Normal University Tianhua College, Shanghai, China \\ ${ }^{2,3}$ University of the Pacific, Stockton, CA, USA \\ amonikateng@163.com, ${ }^{b}$ rhackett@pacific.edu, ${ }^{\mathrm{a}} \mathrm{mdraheim@pacific.edu}$ \\ ${ }^{*}$ Corresponding author
}

Keywords: Young Children, Parental Beliefs, Home Literacy Practices, Reading Interest, Literacy Development.

\begin{abstract}
Using a Chinese sample of 795 parents with preschool-aged children, this quantitative study employed multiple regression analyses to test associations between parental reading beliefs, home literacy practices, children's reading interests, and children's literacy development within a model based on previous American findings [1, 2]. With parent gender, employment and socio-economic status controlled, direct and indirect effects on children's literacy development were found, with both home literacy practices and children's reading interest mediating the relationships between parental reading beliefs and children's literacy development. The study demonstrates that associations within the model of parental reading beliefs may be applicable for families in China. Implications for theory, policy, and practice are discussed.
\end{abstract}

\section{Introduction}

Shared book reading in early childhood is the process in which adults reading to children and interacting with books provide an important context for developing a range of emergent literacy skills in young children [3]. The constructivist learning theory of Vygotsky provided the conceptual framework for this investigation. Vygotsky focused on the connections between people and the sociocultural context; literacy acquisition is viewed as a process of social interaction between children and adults, especially their parents and teachers [4]. Thus, shared book reading is thought to be an effective way of facilitating children's language development and cognitive development $[5,6]$.

Parents' interactive strategies and behaviors during shared reading show strong relations to children's cognitive and language development [7]. Home environments created by parents have a significant effect on children's literacy development $[8,9,10]$. The Parental Reading Beliefs Model of DeBaryshe [1] and Newland and colleagues [2] indicate that parental reading beliefs predict home literacy practices and children's literacy development. Their findings suggested which variables to include and the ordering among them for the model underlying this study (see Figure lin the Appendix). DeBaryshe's model $[1,11]$ indicated that parental beliefs are significantly associated with home literacy practices and children's reading attitudes about books. And Newland and colleagues [2] pointed out additionally that home literacy practices serve a mediating function in the parental reading beliefs model.

Figure 1was provided as a compact way to visualize the hypothesized associations between variables which the research questions address; some of the research questions 
looked at subsets of the variables in isolation of other variables depicted in this overview.

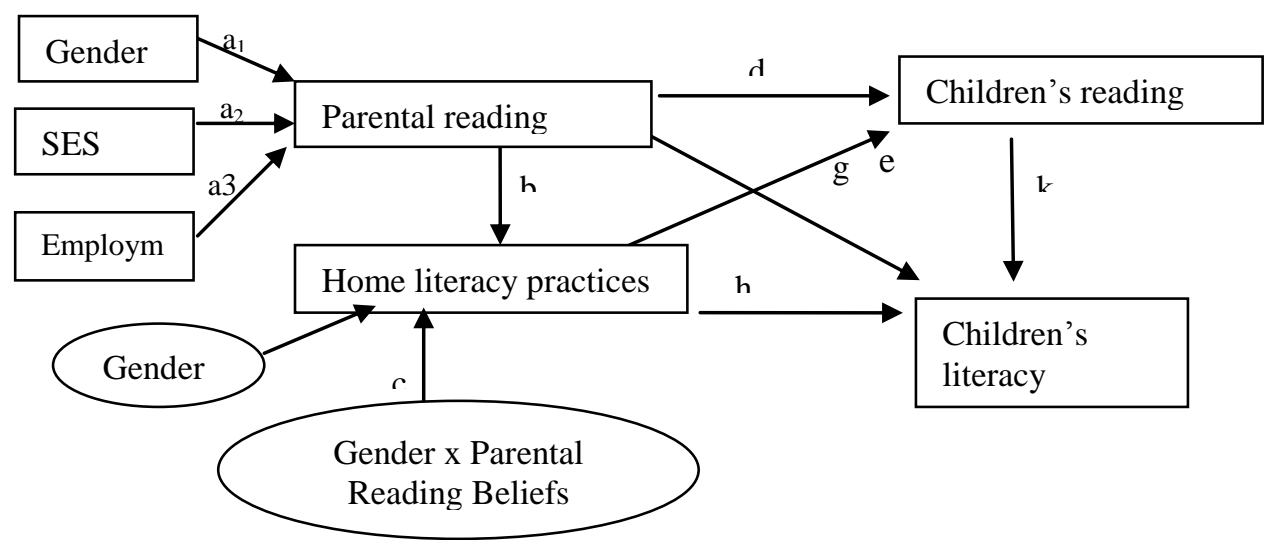

Figure 1: Path Model Overview of Parental Reading Belief System Components

\section{Research Questions}

Based on Figure 1 through Figure 4 in the Appendix, the research questions include:

RQ1) Path a: Are any demographic characteristics of the parent participants (or their children) associated with parental reading beliefs regarding shared book reading?

RQ2) Path b: Is there an association between parental reading beliefs and home literacy practices?

RQ3) Path $d$ : Is there an association between parental reading beliefs and children's reading interest?

RQ4) Path $e$ : Is there an association between parental reading beliefs and children's literacy development?

RQ5) Paths $b, g, d, \& d$ : Is the association between parental reading beliefs and children's reading interest mediated by home literacy practices?

RQ6) Paths $b, h, e \& e^{\prime}$ : Is the association between parental reading beliefs and children's literacy development mediated by home literacy practices?

RQ7) Paths $d, j, e \& e^{*}$ : Is the association between parental reading beliefs and children's literacy development mediated by children's reading interest?

\section{Methods and Data Sources}

A correlational research design was employed. Multiple regression analyses, on data collected from Chinese parents through an on-line survey, were used to evaluate both direct and indirect "effects" of components within a hypothesized model, based on previous American studies, involving parental reading beliefs, home literacy practices, children's reading interests, and children's literacy development.

\section{Participants}

The sample in the study consisted of 795 parents of 36-48 month old children, who had recently enrolled in 18 (mostly urban) schools within two districts in Shanghai(one urban; one rural). Approximately $90 \%$ of the students of these parent participants were enrolled in public schools of various quality with about $30 \%$ each in schools labeled as "model," "first level," and "general." As explained in the procedures, the respondents were a sample of convenience. 


\section{Instruments}

Measures used by other researchers were translated and modified according to Chinese social and cultural conditions for this study. Upon the recommendation of school officials, parents were contacted and asked to complete one survey on-line that contained items from this collection of instruments:

The Parent Reading Belief Inventory was developed by DeBaryshe and Binder [12]. Higher scores reflect more positive parental reading beliefs (PRB) regarding shared book reading. Test-retest reliability was .79 in the earlier study [12]. Cronbach's reliability estimated on the current sample was adequate $(\alpha=.89)$.

Home Literacy Practices. Adopted and revised from Newland et al. [2], this survey consists of three subscales: Family Survey, Read with Child Survey, and Children's Reading Interests, which provided information about demographic characters, home literacy practices, and children's reading interests, respectively. Higher scores on the Read with Child Survey reflect better home literacy practices (HLP) and environments with higher degrees of reading exposure. Higher scores on the Children's Reading Interests (CRI) reflect higher interest and motivation to read. For the current sample, Cronbach's alpha was .759 for the measure of home literacy practices and .830 for the measure of children's reading interest.

The Preschool Parent Developmental Checklist was adapted from Newland et al. [2]. Higher scores on this checklist reflect higher levels of children's literacy development, as reported by parents regarding their 3- to 4-year-old children's performance in oral vocabulary, word knowledge, expressive skills, print-awareness, and writing skills. For the current sample, Cronbach's alpha was .910 for the measure of children's literacy development.

\section{Procedures}

Based on convenience and prior cooperative arrangements between the researcher's affiliated higher education institution, two districts considered to be representative of Shanghai were contacted and 18 of 30 preschool directors agreed to help recruit participants by forwarding information about the survey to parents who had recently enrolled their children in Level 1 of preschool. Using email addresses and chat tools (e.g., QQ), the parents were informed of the study in 2013 and provided with the link to the SurveyMonkey® survey. Elements required on informed consent forms were included at the start of the questionnaire where it was explained to parents that completion and submission of the survey would constitute their consent. An additional 43 parents ( $\sim 5 \%$ of the sample) whose children were enrolled in other schools were recruited through colleagues and friends.

\section{Results}

To address RQ1, multiple regression was used to determine which variables to control in the main analyses. When PRB was simultaneously regressed on demographic characteristics, gender of parent responding, type of employment, and SES (based on income and education combined) were significant. Therefore, these three factors were included as control variables.

To address RQ2 - RQ4, a series a series of sequential multiple regression on PRB was performed where the first block consisted of the three control variables and PRB entered in the second block. As shown in Table 1, after controlling for gender, employment and SES, parent reading beliefs were significantly associated with home 
literacy practices $(\beta=.433)$, children's reading interest $(\beta=.482)$, and children's literacy development $(\beta=.417)$. These standardized regression coefficients represent the total effects of PRB, are of similar magnitude, and account for between $16 \%-21 \%$ of the variation in the three outcomes (HLP, CRI, and CLD).

Table 1. Summary for Effects of Parental Reading Beliefs (PRB) on Home Literacy Practices, Children's Reading Interest, and Children's Literacy Development with SES, Parent's Employment, and Parent's Gender controlled in Sequential Multiple Regressions.

\begin{tabular}{lcccc}
\hline \multicolumn{1}{c}{ Outcome Being Modeled } & $\beta$ & $\Delta R^{2}$ & $\begin{array}{c}\text { Significance of Block 2 } \\
\text { (Adding PRB to the Model) }\end{array}$ \\
\hline HLP: Home literacy practices & .433 & .173 & $F(1,794)=203.78, p<.001$ \\
\hline CRI: Children's reading interest & .482 & .214 & $F(1,790)=248.94, p<.001$ \\
\hline CLD: Children's literacydevelopment & .417 & .161 & $F(1,790)=159.41, p<.001$ \\
\hline
\end{tabular}

To address RQ5 - RQ7, the steps for testing mediation outlined by Baron and Kenny [13] were employed and Sobel Tests were also conducted. This involves a series of regressions where the regression of $\mathrm{Y}$ on $\mathrm{X}$ does and does not include the hypothesized mediator (M) and the regression of $\mathrm{M}$ on $\mathrm{X}$. When the regression coefficient for $\mathrm{X}$ is larger in the model of $\mathrm{Y}$ without $\mathrm{M}$ as compared to the model that includes $\mathrm{M}$, but significant in both models, partial mediation is suggested. The mediation results are summarized in Figures $2-4$ in the appendix. Evidence suggests that home literacy practices partially mediate the effect of parent reading beliefs on children's reading interest (see Figure 2). Also, both home literacy practices (see Figure 3) and children's reading interest (see Figure 4) partially mediate the effect of parent reading beliefs on children's literacy development. Each of the three conclusions was supported by testing for a significant indirect effect using the Sobel Test.

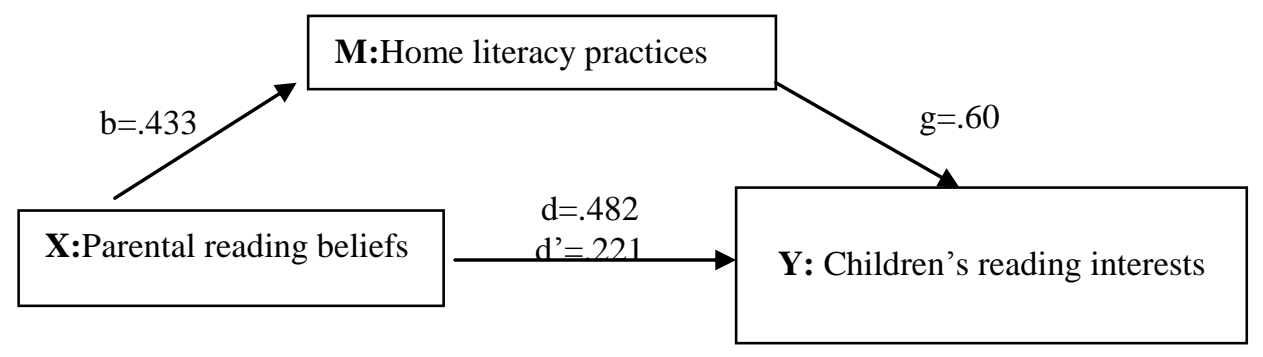

Figure 2.Path Diagram for the Examination of Home Literacy Practices as Mediating Between Parental Reading Beliefs and Children's Reading Interests $(\mathrm{p}<.001$ for all standardized regression coefficients shown). 


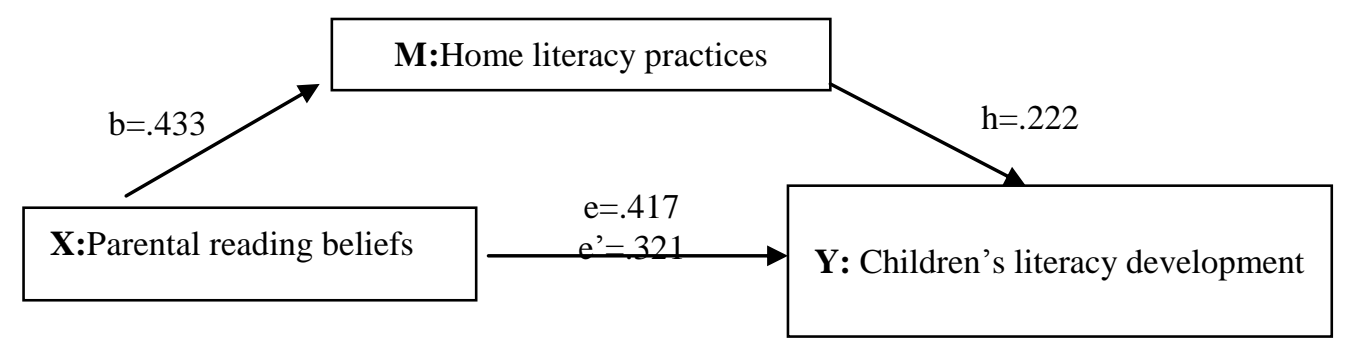

Figure 3.Path Diagram for the Examination of Home Literacy Practices as Mediating Between Parental Reading Beliefs and Children's Literacy Development $(\mathrm{p}<.001$ for all standardized regression coefficients shown).

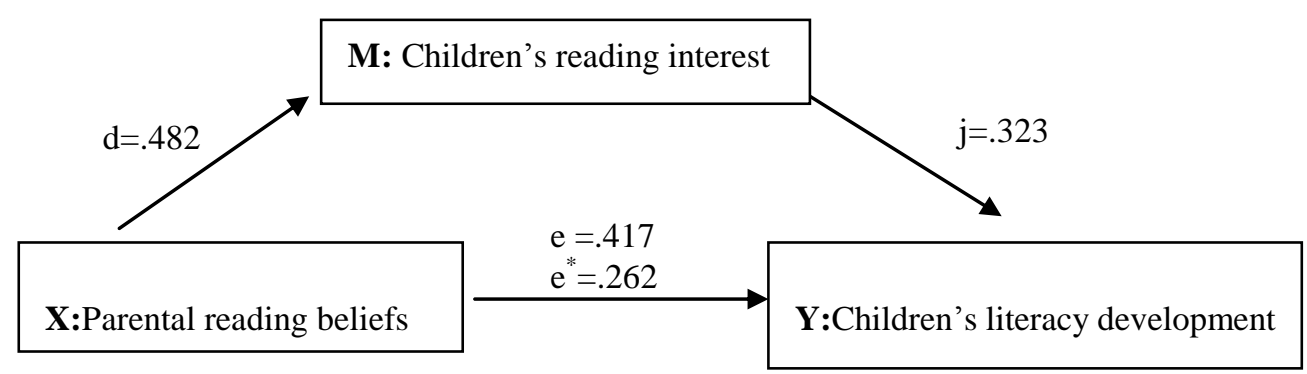

Figure 4.Path Diagram for the Examination of Children's Reading Interests as Mediating Between Parental Reading Beliefs and Children's Literacy Development $(\mathrm{p}<.001$ for all standardized regression coefficients shown).

\section{Conclusion}

The general conclusions to be drawn from these results, based on a sample of Chinese parents of 795 young children, are that (1) parental reading beliefs are influenced by parents' employment, gender, and family SES; (2) parental reading beliefs predict the frequency and quantity of home literacy practices, children's interest in reading, and children's literacy development; and (3) home literacy practices and children's reading interests mediate the influence of parental reading beliefs on children's literacy development. Collectively, the results suggest that a parental reading belief model based on prior research in the United States of American may generalize to a population of families in China. Further research is needed, however, which employs structural equation modeling to test the model, as a whole, against alternative models using diverse samples drawn from regions beyond Shanghai.

\section{References}

[1] DeBaryshe, B. D. (1995). Maternal belief systems: Linchpin in the home reading process. Journal of Applied Developmental Psychology, 16, 1-20. doi: 10.1016/0193-3973(95)90013-6

[2] Newland, L. A., Gapp, S. C., Jacobs, G. M., Reisetter, M. F., Syed, D. C., \& Chih-Hsiu Wu. (2011). Mothers' beliefs and involvement: Links with preschool literacy development. International Journal of Psychology: A Biopsychosocial Approach (9), 67-90.

[3] Kleeck, A.van, \& Vander Woude, J. (2003). Book sharing with preschoolers with language delays, 58-92. In A. van Kleeck, \& S. A. Stahl (Eds.), On reading books to children: Parents and teachers. Mahwah, NJ: Lawrence Erlbaum Associates. 
[4] Crawford, K. (1996) Vygotskian approaches to human development in the information era. Educational Studies in Mathematics, 31, 43-62.

[5] Bowman, B. T., Donovan, M. S., \& Burns, M. S. (Eds.) (2001). Eager to learn: Educating our preschoolers. Washington, DC: National Academy Press. New York: Guilford.

[6] Snow, C. E., Burns, M. S., \& Griffin, P. (1998).Preventing reading difficulties in young children. Washington, DC: National Academy Press.

[7] Landry, S. H. \& Smith, K. E., (2006).The influence of parenting on emergent literacy, 135-162. In D. K. Dickinson \& S. B. Neuman (Eds.), Handbook of early literacy research (Vol.2). New York, NY: Guilford Press.

[8] DeBruin-Parecki, A. (2007).Let's read together: Improving literacy outcomes with the adult-child interactive reading inventory. Baltimore, MA: Paul H. Brookes Publishing.

[9] DeBruin-Parecki, A. (2009).Establishing a family literacy program with a focus on interactive reading: The role of research and accountability. Early Childhood Education Journal, 36(5), 385-392. doi: 10.1007/s10643-008-0299-3

[10] Whitehurst, G. J., \& Lonigan, C. J. (1998).Child development and emergent literacy. Child Development, 3, 848.doi: 10.2307/1132208

[11] DeBaryshe, B.D., Binder, J.C. \& Buell, M. J. (2000). Mothers' implicatit theories of early literacy instruction: Implications for children's reading and writing. Early Children Development and Care, 160, 119-131.

[12] DeBaryshe, B. D., \& Binder, J.C. (1994).Development of an instrument for measuring parental beliefs about reading aloud to young children. Perceptual and Motor Skills, 78, 1303-1311.

[13] Baron, R. M., \& Kenny, D. A. (1986).The moderator-mediator variable distinction in social psychological research: Conceptual, strategic, and statistical considerations. Journal of Personality and Social Psychology, 51(6), 1173-1182. 